\title{
DURABILITY OF THE CUTTING TOOL WITH DIFFERENT THIN LAYERS WHEN INCONEL 718 IS MACHINED
}

\author{
Václav Schorník, Miroslav Zetek, Tomáš Bakša \\ Regional Technological Institute, University of West Bohemia - Faculty of Mechanical Engineering, \\ Univerzitní 22, Pilsen 30614
}

\begin{abstract}
Inconel 718 alloy exhibits high strength and creep-rupture strength at high temperatures. These properties are heavily influenced by heat treatment. Machining, especially milling of this alloy is very difficult because of the high strength and hardness at high temperature. Self-hardening is one of the problems, which leads to enormous tool wear. Productivity of machining is relatively low. This paper is focused on the factors which have the greatest effect on the cutting tool wear and the machined surface quality when the Inconel 718 is machined. There is a description of these factors and their explanations. The experiment for comparing three different cutting tool materials is described. The experiment is also focused on the confirmation of the theoretical information.
\end{abstract}

Keywords: Cooling; Machining; Insert; Milling; Inconel 718
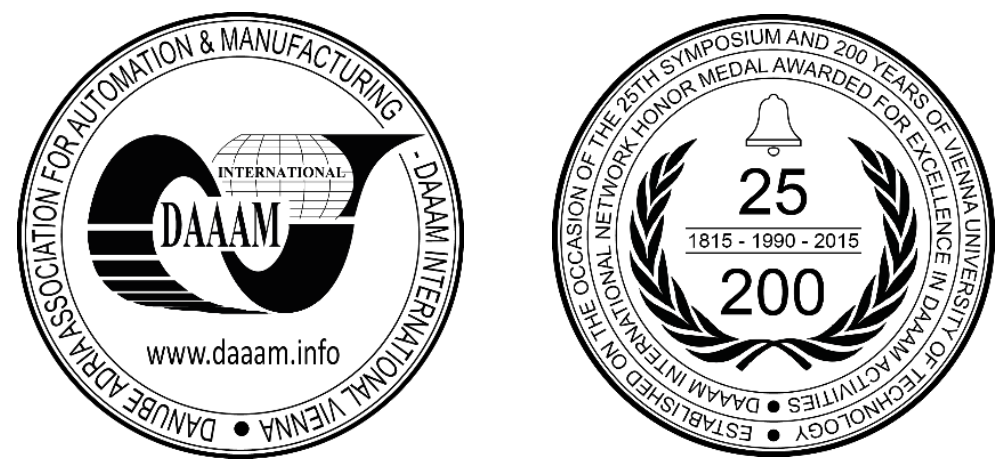

This Publication has to be referred as: Schornik, V[aclav]; Zetek, M[iroslav] \& Baksa, T[omas] (2016). Durability of the Cutting Tool with Different Thin Layers when Inconel 718 is Machined, Proceedings of the 26th DAAAM International Symposium, pp.0678-0682, B. Katalinic (Ed.), Published by DAAAM International, ISBN 978-3-90273407-5, ISSN 1726-9679, Vienna, Austria

DOI: $10.2507 / 26$ th.daaam.proceedings.092 


\section{Introduction}

It is possible to machine this alloy with cutting tools which are made from various materials. Ceramic tools have a high melting point, high hardness, good chemical inertness and high wear resistance. [6] These properties make them usable for the productive machining of Inconel 718. But there is also cutting tool material, such as carbide with thin layers, which can ensure similar properties at a lower price. For example the TiAlN nano-A thin layer is usable for increasing the abrasive resistance of the cutting edge. [7]

Machining Inconel 718 with carbide tools is non-productive. This is due to high abrasive wear which is caused by carbide particles in the structure of Inconel 718. There are also problems with low thermal conductivity - the high temperatures at the face of the tool (especially at higher cutting speeds) leads to enormous tool wear. The difficulty of machining Inconel 718 is caused by low tool life and damaging the machined surface by high temperature and plastic deformation. These last two factors lead to unwanted tensile residual stress. Residual stress has a significant effect on the fatigue strength of the products. The low productivity of the machining of Inconel 718 with carbide cutting tools is also caused by demand on the high torque on the spindle of the machine at low revolutions. All of these problems should be suppressed, because machining of Inconel 718 will be increasingly needed.

There are many studies which are focused on the machining of this alloy. For example, [1],[3],[5] offer a lot of information about the properties of the cutting process when Inconel 718 is machined. But there is no information about usable materials in terms of the finer classification and the comparison of the thin layers which can be used for the machining of this material. This article describes tests which are focused on the differences between some thin layers. As will be described, the type of the thin layer is crucial for the productive machining of this alloy. It may be stated that all of the tested thin layers were designed for machining of this alloy and there are enormous differences between the cutting tool durability when these thin layers were used.

\section{Increasing the cutting tool life}

The absorbed energy during the machining of Inconel 718 is largely converted to heat [1]. There are multiple options which lead to increasing cutting tool life by reducing the temperature at a place near the cutting edge. [8]

High pressure cooling is a way to increase the productivity of machining Inconel 718. It creates lower temperatures near the cutting edges and more effective break off of the chip. The break of the chip is provided by the mechanical action of the pressurized technological fluid. [2] The disadvantage of this method is the impact on the environment due to the increased consumption of the technological fluid. [1]

Minimum quantity lubrication (MQL) is usable for milling, turning and grinding. This method is characterized by the evaporation of the aerosol, which is composed from oil, water and gas which is used for transporting the emulsion to a place near the cutting edge. [3] Selection of the gas which transports the emulsion to the cutting edge is also very important. Experiments with machining Inconel 718 imply that argon is unsuitable for this application, especially because of its low thermal conductivity and heat capacity, which leads to higher temperatures at the cutting edge in comparison to using air. [5] This method may achieve the same results as wet cutting.

Cryogenic cooling is suitable for applications such as grinding, where very high heat is generated. This method is usable for controlling tensile residual stresses which are caused by the heat. Nitrogen is often used as the coolant, because of its price and environmental friendliness. Due to the low cutting tool temperature, increased cutting tool life can be expected. However, the cutting forces are higher because of the absence of material softening at high temperatures. [3]

There are many others methods which can lead to increased cutting tool life when Inconel 718 is machined (such as cooling with pressurized air, plasma assisted machining [1] etc.). The main methods are described.

\section{Machining strategy}

Climb milling is the best way for productive machining with carbide tools. The main reason for this recommendation is the self-hardening of the Inconel 718 by plastic deformation. Using conventional milling leads to selfhardening. It is very important to ensure small chips on the exit of the tool from the material.

The value of the entering angle $\mathrm{Kr}$ should be lower than $45^{\circ}$, because of the increase of the cutting forces. The entering angle $\mathrm{Kr}$ is described by Fig. 1 on the example with a round insert. It may be stated that with the round insert, the $\mathrm{Kr}$ is determined by depth of cut. [4]

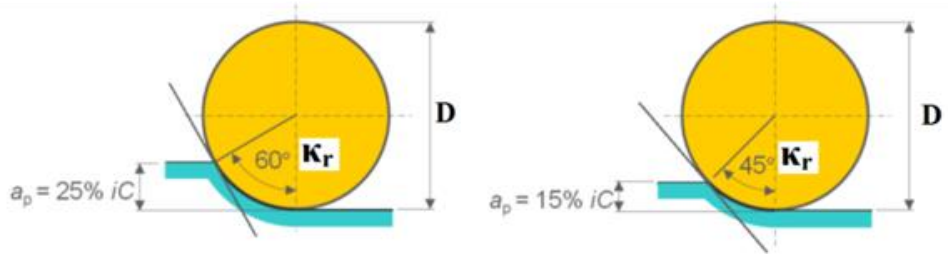

Fig. 1. Description of the angle $\operatorname{Kr}$ [4] 
Radial immersion ae/D $($ see Fig. 2) should be smaller than 0.5 because of the higher chip thickness on entering the material. Radial immersion with ratio ae/Dc= 1 leads to enormous tool wear. [4]

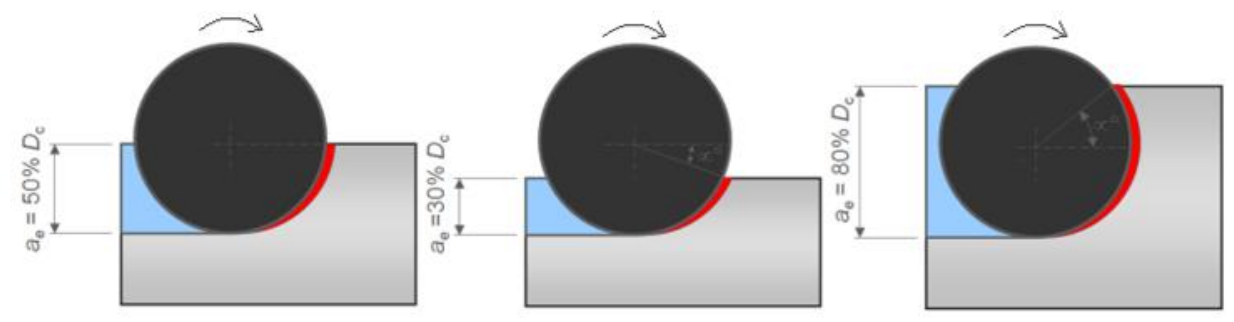

Fig. 2. Description of radial immersion [4]

\section{Usable cutting conditions}

The cutting speed has a very important role in terms of the influence on the residual stress. When the cutting speed is increased, heat generation is also increased. So the heating of the machined surface leads to tensile residual stress, which is not good for the fatigue strength of the machined product. And conversely, with lower cutting speeds (tens of $\mathrm{m} / \mathrm{min}$ ) the residual stress is compressive. The compressive residual stress leads to the increased fatigue strength. [1] The feed speed should be relatively high to ensure the recommended maximum chip thickness $h_{\mathrm{ex}}$. The $\mathrm{h}_{\mathrm{ex}}$ depends on the entering angle $K_{r}$ and radial immersion. The depth of cut depends on the requested value of $K_{r}$.

\section{Influence of the cutting tool on the residual stress}

When dry cutting is used, round and square inserts create the tensile residual stress. This is due to the generated heat. The positive geometry of the cutting edge also leads to tensile residual stress. When negative geometry is used, the residual stress is usually compressive. But in some cases the higher plastic deformation which is caused by negative tool geometry leads an increase in temperature and tensile residual stress. [9]

The cutting conditions are very important in this problem. The round inserts are better for the machined surface quality, because they have longer contact length compared to the square inserts. [4]

\section{Experimental study of the cutting tool efficiency}

We conducted an experiment focused on cutting tool efficiency. Three different insert materials were used. The tool was a face milling cutter with indexable inserts. All inserts are coated by method CVD (chemical vapour deposition). The material of the first insert (I1) is coated by a thin layer with composition $\mathrm{TiN}-\mathrm{Ti}(\mathrm{CN})-\mathrm{Al}_{2} \mathrm{O}_{3}-\mathrm{Ti}(\mathrm{BN})$. The thin layer thickness is $6 \mu \mathrm{m}$. The second insert (I2) has a thinner layer $-4 \mu \mathrm{m}$. The composition of the thin layer is $\mathrm{TiN}_{-} \mathrm{TiB}_{2}$. These two thin layers have a hardness of 89,3 HRA.

The last insert (I3) is I1 modified by a special method. All inserts have the same chip breaker. The clearance angle of all inserts is $\alpha_{0}=11^{\circ}$. The rake angle at the orthogonal plane is $\gamma_{0}=15^{\circ}$. The inserts were placed in the face milling cutter. The cutting conditions were set as in Table 1.

\begin{tabular}{lll}
\hline Cutting conditions & Value & Unit \\
\hline Cutting speed & 20 & {$[\mathrm{~m} / \mathrm{min}]$} \\
Feed per tooth & 0.18 & {$[\mathrm{~mm}]$} \\
Radial depth of cut & 21.4 & {$[\mathrm{~mm}]$} \\
Axial depth of cut & 0.5 & {$[\mathrm{~mm}]$} \\
Entering angle & 24 & {$\left[{ }^{\circ}\right]$} \\
Pressure of coolant & 20 & {$[\mathrm{bar}]$} \\
Concentration of coolant & 6.5 & {$[\%]$} \\
\hline
\end{tabular}

Table 1. Cutting conditions

In this experiment, the cutting tool wear and cutting forces were monitored. The tool wear was monitored on a Multicheck PC 500 optical microscope. The flank wear $\mathrm{VB}_{\mathrm{B}}$ was monitored. $\mathrm{VB}_{\mathrm{B}}=150 \mu \mathrm{m}$ is the limit for the flank wear, 
which was achieved by all the inserts. The tool wear was monitored after $3.56 \mathrm{~min}$ in cut. The cutting forces were monitored with a Kistler 9255C dynamometer. The milling process was carried out on a MCV 750 CNC machine.

\subsection{Analysis of the results}

The longest time in cut was achieved by the I2. This is due to the sliding properties and durability of the TiN$\mathrm{TiB}_{2}$ thin layer. The time in cut of this insert is $21.36 \mathrm{~min}$. It may be stated that the radial depth of cut is $50 \%$ of the cutting diameter. This leads to the lower durability of the cutting tool inserts. It is very surprising that the I 3 withstands a longer time in the cut than I1. This fact can be attributed to the mechanical modification of the cutting edge such as strain hardening and changes in the insert micro geometry. It is known, that these modifications have a crucial influence on the cutting tool life. There are differences in cutting tool life, when the sharp, facet or radius cutting edge is used. [10]. It may be stated that I1 and I2 are designated for the milling of Inconel 718. The cutting conditions were designed according to the catalogue values. All of these results are illustrated in Fig. 3 (a).
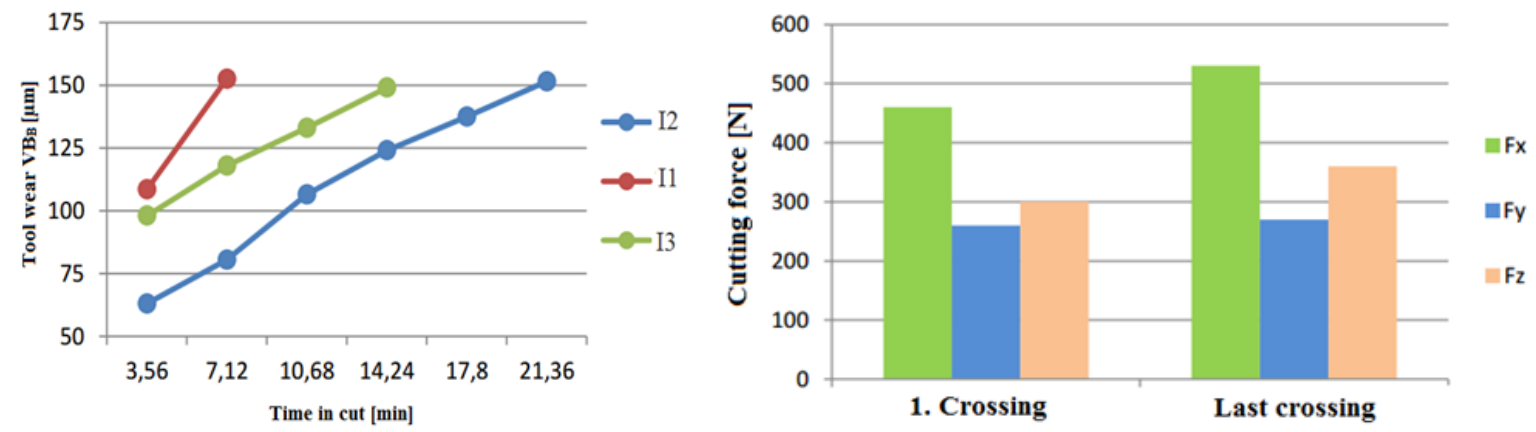

Fig. 3. (a) The dependence of the tool wear on the time in cut; (b) Cutting forces

As was stated, the cutting forces were monitored. Fig. 3 (b) shows the chart illustrating the course of the forces in the direction of the relevant axis. The forces are shown which were generated with insert I2. Fig. 4 (a) describes the appropriate direction of the forces. It is clear that the cutting forces were higher at the last crossing (when the $\mathrm{VB}_{\mathrm{B}}$ reaches $150 \mu \mathrm{m})$. It is interesting that the force in direction of the axis $F_{x}$ is increased more than the other forces. It can be expected that this phenomena is caused by the tool wear on the rake of the insert. The flank wear is illustrated in Fig. 4 (b). It can be seen that the flank wear is uniform, without notch wear.
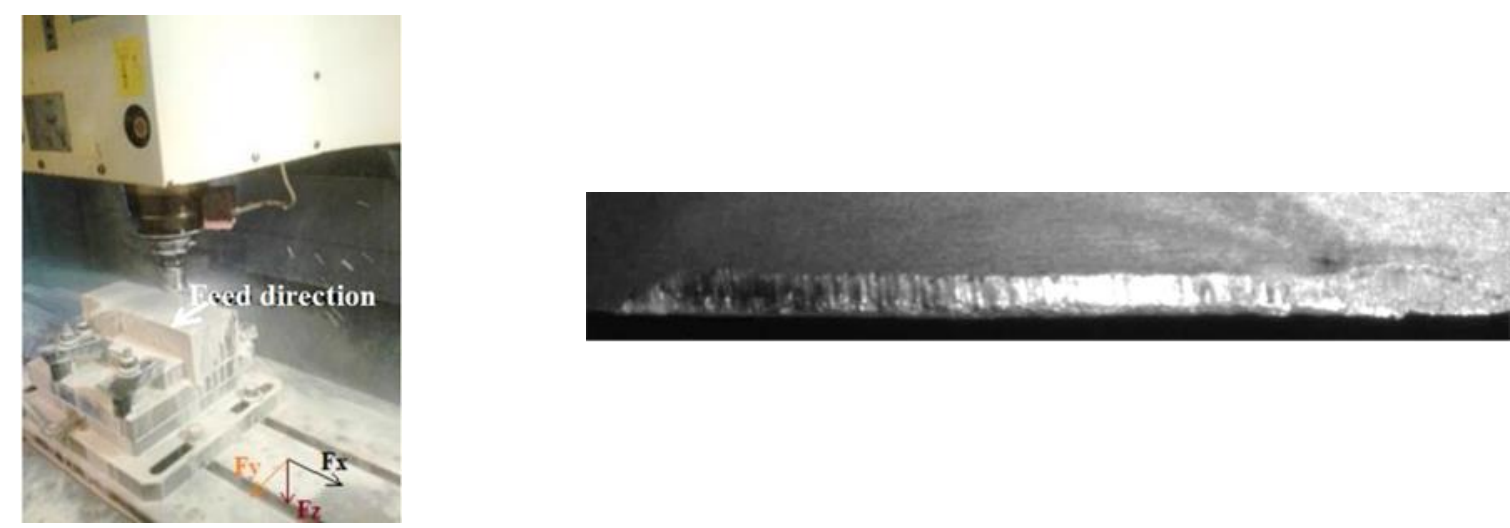

Fig. 4 (a) Description of the force direction; (b) Flank wear - VBB=150 $\mu \mathrm{m}$, Insert I2

The insert I1 had $\mathrm{VBB}=150 \mu \mathrm{m}$ after $7.12 \mathrm{~min}$ in cut. More repetitions were performed with the same results. This experiment shows that it is possible to machine the Inconel 718 by carbide cutting tools with relative high cutting tool life, but only with the right thin layer and usable cutting conditions. The insert 3 have a special mechanical modification, which ensure higher cutting tool life. So the influence of the shape of the cutting edge is confirmed.

\section{Conclusion}

The factors which have the greatest effect on tool durability were described. Recommendations for the more effective machining of this alloy are given. The main problem is the correct selection of the tool material. The experiment proved that the best thin layer material is $\mathrm{TiN}_{-} \mathrm{TiB}_{2}$. The insert with this thin layer withstands $21.36 \mathrm{~min}$ in cut The insert I1 with the thin layer $\mathrm{TiN}-\mathrm{Ti}(\mathrm{CN})-\mathrm{Al}_{2} \mathrm{O}_{3}-\mathrm{Ti}(\mathrm{BN})$ could only withstand $7.12 \mathrm{~min}$ in cut. These two inserts are designed for 
nickel-based super alloys, so the difference between these inserts is surprising. It is possible that the cutting conditions which were selected are inappropriate for the insert I1, but they were chosen according to the manufacturer's catalogue. Further research will be focused on different cooling regimes. It can be expected that conventional cooling is less effective than high pressure cooling, taking account of the different direction of coolant supply.

\section{Acknowledgements}

The present contribution has been prepared under project LO1502 'Development of the Regional Technological Institute " under the auspices of the National Sustainability Programme I of the Ministry of Education of the Czech Republic aimed to support research, experimental development and innovation.

\section{References}

[1] D. Dudzinski, A. Devillez, A. Moufki, D. Larrouquère, V. Zerrouki, J. Vigneau. A review of developments towards dry and high speed machining of Inconel 718 alloy. [Online] International Journal of Machine Tools and Manufacture, Volume 44, Issue 4, March 2004, Pages 439-456, ISSN 0890-6955, http://dx.doi.org/10.1016/S08906955(03)00159-7.

[2] Rosemar B. da Silva, Álisson R. Machado, Emmanuel O. Ezugwu, John Bonney, Wisley F. Sales Tool life and wear mechanisms in high speed machining of Ti-6Al-4V alloy with PCD tools under various coolant pressures.. Journal of Materials Processing Technology, Volume 213, Issue 8, August 2013, Pages 1459-1464, ISSN 09240136, http://dx.doi.org/10.1016/j.jmatprotec.2013.03.008.

[3] Ezugwu, E.O. High speed machining of aero-engine alloys. J. Braz. Soc. Mech. Sci. \& Eng. [online]. 2004, vol.26, n.1, pp. 1-11. ISSN 1678-5878. http://dx.doi.org/10.1590/S1678-58782004000100001.

[4] Sandvik. Application Guide. [Online] C-2920:034 US/01 @ C AB Sandvik Coromant 2010.08, http://www.sandvik.coromant.com/sitecollectiondocuments/downloads/global/technical\%20guides/en-us/c-2920034.pdf

[5] Y. Kamata, T. Obikawa. High speed MQL finish-turning of Inconel 718 with different coated tools. Journal of Materials Processing Technology, Volumes 192-193, 1 October 2007, Pages 281-286, ISSN 0924-0136, http://dx.doi.org/10.1016/j.jmatprotec.2007.04.052.

[6] R. Cep, A. Janasek, J.Petru. Tungaloy Ceramic Cutting Tools at Interrupted Machining, Chapter 35 in DAAAM International Scientific Book 2012, pp. 401-412, B. Katalinic (Ed.), Published by DAAAM International, ISBN 9783-901509-86-5, ISSN 1726-9687, Vienna, Austria DOI: 10.2507/daaam.scibook.2012.35

[7] J. Kyncl, L. Beránek, K. Kolařík, Z. Pala, The Research of the Surface Profile after Profiling of Inconel 738LC, Procedia Engineering, Volume 69, 2014, Pages 974-979, ISSN 1877-7058, http://dx.doi.org/10.1016/j.proeng.2014.03.078. (http://www.sciencedirect.com/science/article/pii/S1877705814003245)

[8] V. Schorník, M. Zetek, M. Daňa, The Influence of Working Environment and Cutting Conditions on Milling Nickel - Based Super Alloys with Carbide Tools, Procedia Engineering, Volume 100, 2015, Pages 1262-1269, ISSN 18777058 , (http://www.sciencedirect.com/science/article/pii/S1877705815005196) http://dx.doi.org/10.1016/j.proeng.2015.01.492.

[9] R.M. Arunachalam, M.A. Mannan, A.C. Spowage. Surface integrity when machining age hardened Inconel 718 with coated carbide cutting tools. [Online] International Journal of Machine Tools and Manufacture, Volume 44, Issue 14, November 2004, Pages 1481-1491, $\quad$ ISSN $0890-6955$ http://www.sciencedirect.com/science/article/pii/S0890695504001270

[10] M. Zetek, I. Česáková, V. Švarc, Increasing Cutting Tool Life when Machining Inconel 718, Procedia Engineering, Volume 69, 2014, Pages 1115-1124, ISSN 1877-7058, http://dx.doi.org/10.1016/j.proeng.2014.03.099. (http://www.sciencedirect.com/science/article/pii/S1877705814003452) 